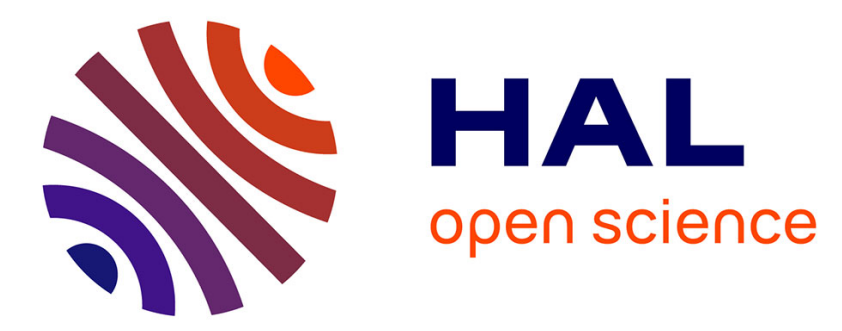

\title{
Electron-molecular vibration coupling in (DMtTTF)Br and (o-DMTTF)2[W6O19] salts studied by vibrational spectroscopy
}

Andrzej Łapiński, Damian Jankowski, Roman Swietlik, Eric W. Reinheimer, Marc Fourmigué

\section{To cite this version:}

Andrzej Łapiński, Damian Jankowski, Roman Swietlik, Eric W. Reinheimer, Marc Fourmigué. Electron-molecular vibration coupling in (DMtTTF)Br and (o-DMTTF)2[W6O19] salts studied by vibrational spectroscopy. Synthetic Metals, 2014, 188, pp.92-99. 10.1016/j.synthmet.2013.11.004 . hal-00990352

\section{HAL Id: hal-00990352}

\section{https://hal-univ-rennes1.archives-ouvertes.fr/hal-00990352}

Submitted on 13 May 2014

HAL is a multi-disciplinary open access archive for the deposit and dissemination of scientific research documents, whether they are published or not. The documents may come from teaching and research institutions in France or abroad, or from public or private research centers.
L'archive ouverte pluridisciplinaire HAL, est destinée au dépôt et à la diffusion de documents scientifiques de niveau recherche, publiés ou non, émanant des établissements d'enseignement et de recherche français ou étrangers, des laboratoires publics ou privés. 


\title{
Electron-molecular vibration coupling in (DMtTTF)Br and $(o-D M T T F)_{2}\left[\mathrm{~W}_{6} \mathbf{O}_{19}\right]$ salts studied by vibrational spectroscopy
}

\author{
Andrzej Łapiński ${ }^{1,}{ }^{*}$, Damian Jankowski ${ }^{1}$, Roman Świetlik ${ }^{1}$, \\ Eric W. Reinheimer ${ }^{2,3}$, Marc Fourmigué ${ }^{3}$
}

${ }^{1}$ Institute of Molecular Physics, Polish Academy of Sciences, M. Smoluchowskiego 17, 60-179 Poznań, Poland

\author{
${ }^{2}$ Department of Chemistry, Texas A\&M University, College Station, TX 77842-3012, USA \\ ${ }^{3}$ Institut des Sciences Chimiques de Rennes, UMR 6226 CNRS-Université Rennes 1, Campus \\ de Beaulieu, 35042 Rennes, France
}

\begin{abstract}
A novel 1:1 salt encompassing radical cations of DMtTTF $(\mathrm{DMtTTF}=$ dimethyltrimethylenetetrathiafulvalene) and the $\mathrm{Br}^{-}$anion has been synthesized. Close inspection of the salt's solid state structure revealed the presence of quasi-isolated dimers containing DMtTTF radical cations, a specific arrangement whereby the microscopic parameters of $\mathrm{DMtTTF}^{\circ+}$ might be studied. Analysis of the corresponding single crystal IR and Raman spectra of (DMtTTF)Br allowed us to study the material's electronic and vibrational structure and to evaluate the electron-molecular coupling constants via the isolated dimer model. Additionally, using previously published IR data, analogous calculations were performed on the salt (oDMTTF $)_{2}\left[\mathrm{~W}_{6} \mathrm{O}_{19}\right](o-\mathrm{DMTTF}=o-3,4$-dimethyltetrathiafulvalene $)$, which also contains well isolated dimers of o-DMTTF radical cations. These calculations revealed that the coupling constants for the unsymmetrical donors studied herein are comparable to those for symmetric TTF derivatives.
\end{abstract}


Keywords: DMtTTF and DMTTF salts; IR and Raman spectroscopy; electron-molecular vibration (EMV) coupling effect; dimer model

\footnotetext{
*Corresponding author Tel.: +48 618695 201; fax: +48 618684524

E-mail address: lapinski@ifmpan.poznan.pl
}

\section{Introduction}

Within the field of organic conductors, it was very early realized that electrons in these materials couple strongly with intramolecular vibrations. This interaction is very important for understanding the physical properties of these systems which can display both activated and non-activated conductivity as well as superconductivity [1]. Infrared (IR) spectroscopy is a powerful method whereby molecular parameters, such as the EMV coupling constants, might be determined [2-4].

The first experimental determination of the EMV coupling constants was performed on quasi-one-dimensional conductors containing the organic donor TCNQ (TCNQ = tetracyanoquinodimethane). For TCNQ salts possessing uniform or dimerized stacks, the phase phonon or isolated dimer models respectively were successfully applied in order to estimate the EMV coupling constants [5-8]. Originally developed for the salt K-TCNQ, with its well-isolated $(\mathrm{TCNQ})_{2}{ }^{2-}$ dimers, the latter isolated dimer model provided a means by which the experimental determination of the coupling constants in this material could be achieved [7]. In addition to doubly-charged TCNQ dimers, the model also found utility in salts having TCNQ dimers containing one electron as the totally symmetric TCNQ vibrations were found to couple to the charge transfer between the charged and neutral molecules [9]. Subsequently, the isolated cluster model was also successfully applied to systems having greater than two TCNQ molecules [10-12]. Fitting the IR spectra of various TCNQ salts via 
multiple models afforded the unique opportunity to experimentally determine fundamental molecular parameters such as the EMV coupling constants and compare them to those obtained through theoretical calculations [13].

As mentioned above, models of EMV coupling are universal and were successfully applied to IR spectra of charge-transfer salts formed by TTF (TTF = tetrathiafulvalene) and its derivatives with various acceptors [14]. More specifically, the dimer model has proven especially useful in determining the coupling constants for charge transfer materials containing TTF derivatives. For example, reliable values for the EMV constants were obtained for the salt (BEDT-TTF $)_{2}\left[\mathrm{Mo}_{6} \mathrm{O}_{19}\right]$ (BEDT-TTF = bis(ethylenedithio)tetrathiafulvalene) which contained well-isolated (BEDT-TTF ${ }_{2}{ }_{2}{ }^{2+}$ dimers $[15]$.

According to symmetry considerations, in linear approximation for non-degenerated molecular orbital only the totally symmetric vibrational modes can couple with electrons $[6$, 16-17]. For other symmetry modes, the electron-vibrational interaction is forbidden by the selection rules and is only correct if the molecules within the dimer have the same symmetry [16]. When considering the dimer, where the molecules are asymmetric with respect to one another, if those molecules are different or inequivalent, their modes are no longer degenerate and couple both in-phase and out-of-phase. In this case, the lack of an inversion center suppresses the mutual exclusion rule leading to all of the modes for the constituent molecules within the dimer becoming both IR and Raman active. Additionally, all of their symmetric modes can then couple to the CT electron [18]. Moreover, if we consider the sufficiently fast charge transfer between the dimer molecules due to electromagnetic radiation, their nuclear configurations do not have time to change in response to the charge transfer and their molecular vibrations arise as the result of the relaxation to each molecule's respective equilibrium configuration. In this case, the symmetry type of the arising vibrational modes 
depends not only on the final and initial state symmetries, but also on that of the intermediate states from which the transferred charge among the neighboring molecules belongs. These facts suggest that in some cases non-totally symmetric modes can be also coupled [19].

Herein, we describe a new 1:1 charge transfer salt formed via electrochemical oxidation of the unsymmetrical donor DMtTTF (Scheme 1) in the presence of $\mathrm{Br}^{-}$anions. Within the structure of this salt, the donors are arranged into well-isolated $\left(\mathrm{DMtTTF}^{+}\right)_{2}{ }^{2+}$ dimers intimating that the dimer model for EMV coupling should be very well applicable. Subsequently, we also used the dimer model for fitting the IR spectrum of the (oDMTTF $)_{2}\left[\mathrm{~W}_{6} \mathrm{O}_{19}\right]$ salt containing $\left(o-\mathrm{DMTTF}^{+}\right)_{2}{ }^{2+}$ dimers and calculated the EMV coupling constants for its $o$-DMTTF ${ }^{\circ+}$ cations. The synthesis, structure and IR spectrum for this latter charge transfer salt, with its cations of the unsymmetrical donor $o$-DMTTF (Scheme 1) and the dianionic Lindquist polyoxoanion $\left[\mathrm{W}_{6} \mathrm{O}_{19}\right]^{2-}$ were the subject of our recent report [20].

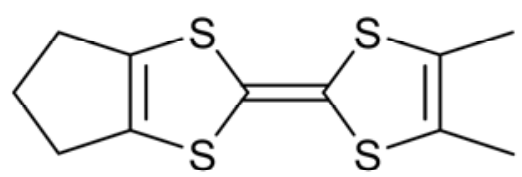

DMtTTF

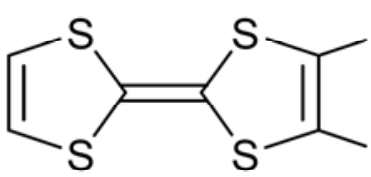

o-DMTTF

Scheme 1. Molecular structure of the DMtTTF and $o$-DMTTF donors

In the IR spectra for salts formed by unsymmetrical TTF derivatives such as $o$ DMTTF, DMtTTF, EDO-TTF, and DOEO, one observes vibrational features suggestive of EMV coupling to intramolecular vibrations of donors, especially those related to $\mathrm{C}=\mathrm{C}$ stretching [21-26]. Similarly, in the IR spectra of the salts (DMtTTF)Br and (oDMTTF $)_{2}\left[\mathrm{~W}_{6} \mathrm{O}_{19}\right]$, we also find a clear evidence of the EMV coupling to $\mathrm{C}=\mathrm{C}$ stretching modes. It should be emphasized that both donor molecules belong to the point group $C_{2 \mathrm{v}}$, i.e. they have no center of symmetry and in crystal structures their local point symmetries can be lowered. The aim of the present study is to evaluate experimentally the EMV coupling constants for the unsymmetrical donors $o$-DMTTF and DMtTTF. 


\section{Experimental}

Single crystals of the $1: 1$ salt (DMtTTF)Br salt were grown by the electrocrystallization method using Pt electrodes. Electrolyte solution was prepared by dissolving DMtTTF $(12.1 \mathrm{mg})$ and $\left[\mathrm{PPh}_{4}\right][\mathrm{Br}](201.6 \mathrm{mg}, 0.480 \mathrm{mmol})$ in freshly distilled 1,1,2-trichloroethane $(10 \mathrm{~mL})$. Crystals were grown at room temperature at a constant current density of $0.5 \mu \mathrm{A}$. After two weeks the crystals were harvested, washed with a small amount of freshly distilled 1,1,2-trichloroethane, and allowed to dry in air.

Crystal structure studies were performed on Nonius KappaCCD Diffractometer with graphite-monochromated Mo-K $\alpha$ radiation $(\lambda=0.71073 \AA)$. The structures were solved by direct methods (SHELXS-97) and refined (SHELXL-97) by full-matrix least-squares methods as implemented in the WinGX software package. Multi-scan absorption corrections were performed using SADABS. Hydrogen atoms were introduced at calculated positions (riding model), included in structure factor calculations and not refined. Crystallographic data are summarized in Table I. CCDC file 830864 contains the supplementary crystallographic data for this paper. These data can be obtained free of charge from The Cambridge Crystallographic Data Centre via www.ccdc.cam.ac.uk/data_request/cif.

Polarized reflectance measurements of the salt (DMtTTF)Br in the frequency range from 700 to $16000 \mathrm{~cm}^{-1}$ were performed on single crystals using an FT-IR Bruker Equinox 55 spectrometer equipped with a Bruker Hyperion 1000 microscope. The optical conductivity spectra were obtained by Kramers-Kronig analysis of the reflectance data for the salts (DMtTTF) Br and (o-DMTTF $)_{2}\left[\mathrm{~W}_{6} \mathrm{O}_{19}\right]$ reported in Ref. 25. The low-frequency data were extrapolated to zero frequency assuming a constant value. For frequency values above the highest point, the reflectance data were approximated by $\mathrm{R} \sim \omega^{-2}$ while those above $10^{6} \mathrm{~cm}^{-1}$ by $\mathrm{R} \sim \omega^{-4}$. Single crystal Raman spectra of (DMtTTF) Br were measured in a backward scattering 
geometry using Labram HR Horiba Jobin Yvon with a He-Ne laser $\left(\lambda_{\text {exc }}=632.8 \mathrm{~nm}\right)$. The Raman spectra were recorded in the frequency range $150-3500 \mathrm{~cm}^{-1}$ with a spectral resolution better than $2 \mathrm{~cm}^{-1}$. In order to avoid sample overheating, the power of the laser beam was reduced to $\sim 0.1 \mathrm{~mW}$.

The quantum chemical calculations of the $\mathrm{DMtTTT}^{\circ+}$ and $o$-DMTTF${ }^{*+}$ cations were carried out using the Gaussian 03 program with the $6-311++G(d, p)$ basis set [27]. The hybrid gradient-corrected exchange functional proposed by Becke was combined with the gradientcorrected correlation functional of Lee, Yang, and Parr [28-29]. The initial geometry in the optimization process was taken from X-ray data. The geometries of the radical cations were fully optimized at the B3LYP/6-311++G(d,p) level of theory and those structures were checked by analysis of the harmonic vibrational frequencies to verify whether they are at minima, saddle points or stationary points of higher orders. Only positive eigenvalues of the Hessian matrix were obtained, proving that the calculated geometry was at a minimum on the potential energy surface. DFT orbitals were obtained by solving the Kohn-Sham equation which included both exchange and correlation terms. Recently, a normal mode analysis for neutral DMtTTT and $o$-DMTTF molecules as well as their cations was already performed [27, 29].

\section{Results and Discussion}

\subsection{Crystal structures of (DMtTTF)Br and (o-DMTTF $)_{2}\left[\mathrm{~W}_{6} \mathrm{O}_{19}\right]$}

The crystal structure data for the 1:1 salt (DMtTTF)Br collected at room temperature is presented in Table I. This salt crystallizes in the monoclinic pace group $P 2{ }_{1} / c$ and contains both cations and anions on general positions. As shown in Figure 1, the oxidized molecules are organized into strongly-dimerized chains with very short intradimer $\mathrm{S} \cdots \mathrm{S}$ contacts at 3.386(7) and 3.502(7) $\AA$, while the contacts between the sulfur atoms within their interdimer 
analogues exceeds $3.9 \AA$ A. Furthermore, the stacks are oriented perpendicular to each other, an orientation similar to those observed in TMTTF salts that prohibits any sizeable lateral $\mathrm{S} \cdots \mathrm{S}$ contacts. In addition, no $\mathrm{C}-\mathrm{H} \cdots \mathrm{Br}$ hydrogen bonds were observed upon closer inspection. As a result of these structural features, the $(\mathrm{DMtTTF})_{2}{ }^{2+}$ dimers can be considered well-isolated from one another and that the unpaired electrons are strongly localized within the dimeric unit. The intramolecular bond lengths for the TTF core of the $\mathrm{DMtTTF}^{\circ+}$ cation are given in Table II. Given the donor's unsymmetrical nature, for clarification, those bonds from the fulvalene ring having only hydrogen atoms is denoted by an ' $R$ ' while those from the ring possessing methyl groups are denoted by ' $\mathrm{Me}$ '.

Recently, a charge transfer salt containing radical cations of the unsymmetrical donor $o$-DMTTF and the closed shell, dianionic Lindquist polyoxometalate $\left[\mathrm{W}_{6} \mathrm{O}_{19}\right]^{2-}$ was reported [20]. In this salt, the donor molecules aggregate in a head-to-tail manner, forming strong faceto-face doubly charged $\left(o-\mathrm{DMTTF}^{+}\right)_{2}{ }^{2+}$ dimers that lie nearly parallel to the $a b$ plane (see Fig. 2). Given the size of the $\left[\mathrm{W}_{6} \mathrm{O}_{19}\right]^{2-}$ anion within the structure, the dimers are effectively well isolated from one another in the solid state. The detailed X-ray structural analysis, including a description of its array of hydrogen bonding interactions, was discussed in Ref. 20.

\subsection{Raman and IR spectra}

The single crystal Raman spectrum for (DMtTTF)Br is shown in Fig. 3. Within the region of $\mathrm{C}=\mathrm{C}$ stretching, one observes three bands at 1412,1507 , and $1587 \mathrm{~cm}^{-1}$ assigned to the stretching of the central $\mathrm{C}=\mathrm{C}$ bond, and the out-of-phase and in-phase stretching of the ring bonds, respectively. As DMtTTF has no center of symmetry, the mode related to the outof-phase $\mathrm{C}=\mathrm{C}$ ring stretching can be viewed in the Raman spectrum. Other bands are assigned as follows: 1034 and $933 \mathrm{~cm}^{-1}\left(\mathrm{CH}_{3}\right.$ wagging), $960 \mathrm{~cm}^{-1}$ (C-S and C-C stretching), 510 and $451 \mathrm{~cm}^{-1}$ (in-phase and out-of-phase fulvalene ring breathing) and $221 \mathrm{~cm}^{-1}$ (deformation). 
Single crystal IR reflectance spectra of the (DMtTTF)Br salt for two polarizations (parallel and perpendicular to the $a$-axis) are displayed in Fig. 4a. Within these spectra, we observe a strong electronic absorption centred at $\sim 7700 \mathrm{~cm}^{-1}$ assigned to the charge transfer transition between the fully ionized $\mathrm{DMtTTF}^{\circ+}$ molecules and an intense narrow vibrational feature at $\sim 1338 \mathrm{~cm}^{-1}$ assigned to the electron-molecular vibration (EMV) coupling of the $\mathrm{C}=\mathrm{C}$ stretching mode with the charge transfer transition at $7700 \mathrm{~cm}^{-1}$. It has been well established in spectroscopic studies on TTF derivatives that the largest EMV coupling constants are attributed to coupling with the central $\mathrm{C}=\mathrm{C}$ bond stretching vibration. As the band at $1338 \mathrm{~cm}^{-}$ ${ }^{1}$ constituted the largest such vibrational feature based on magnitude, it was assigned to this coupling mode; however in comparison with the Raman data it is shifted towards lower wavenumbers by $\sim 74 \mathrm{~cm}^{-1}$ due to this strong coupling. It is also important to note that within the IR spectrum, at the E//a orientation, we also observed smaller vibrational features at 1436 and $1498 \mathrm{~cm}^{-1}$ corresponding to the electron-molecular vibration (EMV) coupling of the $\mathrm{C}=\mathrm{C}$ ring anti-phase and in-phase stretching, respectively

The IR reflectance spectra of $(o-\mathrm{DMTTF})_{2}\left[\mathrm{~W}_{6} \mathrm{O}_{19}\right]$ single crystals show also a clear evidence of interaction with the charge transfer transition at $\sim 10250 \mathrm{~cm}^{-1}$ (Fig. $4 \mathrm{~b}$ ): within the region of $\mathrm{C}=\mathrm{C}$ stretching we observe a strong vibrational feature at $1345 \mathrm{~cm}^{-1}$ as well as much weaker bands at 1465 and $1553 \mathrm{~cm}^{-1}$, which correspond to the $\mathrm{C}=\mathrm{C}$ central, and $\mathrm{C}=\mathrm{C}$ ring anti-phase and in-phase stretching modes respectively (see Fig. 6). It is important to note that by comparison, the charge transfer band of $(o \text {-DMTTF })_{2}\left[\mathrm{~W}_{6} \mathrm{O}_{19}\right]$ lies at much higher energy than its analogue within (DMtTTF)Br. The energy of this transition is proportional to the onsite repulsion energy between two charges (Hubbard $U$ parameter). By a first approximation, the higher energy of the transition, in comparison to other TTF derivatives, could be associated with a larger $U$. However, it is also possible that the presence of hydrogen bonding between the donors and the anions is also having an effect. For the Raman spectrum of $(o-$ 
$\mathrm{DMTTF})_{2}\left[\mathrm{~W}_{6} \mathrm{O}_{19}\right]$, within the region of $\mathrm{C}=\mathrm{C}$ stretching vibrations, three bands at $1417 \mathrm{~cm}^{-1}$, 1483 , and $1556 \mathrm{~cm}^{-1}$ were found and assigned to the stretching of central $\mathrm{C}=\mathrm{C}$ bond, as well as the out-of-phase and in-phase stretching of ring bonds respectively [20].

In the investigated salts, the shifting of vibrational bands toward lower wavenumbers with respect to the Raman data and, moreover, with a characteristic antiresonance dip, provide evidence of their interaction with the charge transfer transition. This effect is quite visible for (DMtTTF)Br salt where antiresonance dip at $1326 \mathrm{~cm}^{-1}$ was noted (see Fig. 5); the band at $1338 \mathrm{~cm}^{-1}$ displays a characteristics reminiscent of an asymmetric Fano lineshape [30]. When the electric field is polarized along a chain of molecules, the interaction between the electronic absorption and phonon frequencies gives rise to an asymmetric Fano lineshape of bands [30]. The analysis of the Fano-effect, in conjunction with the Raman data, can lead to quantitative predictions for the various electron phonon couplings [31].

\subsection{Calculation of EMV coupling constants}

Much like the IR spectra for the recently published (o-DMTTF) $2\left[\mathrm{~W}_{6} \mathrm{O}_{19}\right]$ whose structure contained quasi-isolated dimers [20], the IR spectra for (DMtTTF)Br can also be analyzed in terms of the isolated dimer model. For both salts, due to the coupling, the vibrational modes borrow intensity from the nearby $\mathrm{CT}$ electronic transition and occur at frequencies lower than their corresponding Raman bands. The IR spectra of the investigated salts are dominated by the occurrence of very strong electronic bands (CT transitions) that are polarized perpendicularly to the molecular planes.

Using the Rice's model for both compounds, we calculated the frequency-dependent conductivity for the isolated dimer [8]. For the electronic part we have only considered the ground and charge-transfer states, disregarding the presence of excitonic intramolecular states. Furthermore, the coupling between electrons and the molecular vibrations is assumed 
to occur through the phononic modulation of the on-site energy. Using linear-response theory, the frequency-dependent conductivity in the direction of the CT transition is given by the formula $[8](\hbar=1)$ :

$\sigma(\omega)=-i \omega \frac{e^{2} a^{2}}{4} \frac{N}{V} \frac{\chi(\omega)}{(1-\tilde{\chi}(\omega) D(\omega))}$

where $e$ is the electronic charge, $a$ the intradimer distance, $N / V$ the number of dimers per unit volume, $\quad \chi(\omega)=8 c_{1}^{2} \omega_{C T} /\left(\omega_{C T}^{2}-\omega^{2}-i \omega \gamma_{e}\right)$ the $\mathrm{CT}$ electronic susceptibility and $\widetilde{\chi}(\omega)=\chi(\omega) / \chi(0)$ its reduced form; $c_{1}$ is the expansion coefficient of the eigenstate. The $\mathrm{EM} V$ coupled phonons are described by the phonon propagator:

$$
D(\omega)=\sum_{\alpha} \frac{\lambda_{\alpha} \omega_{\alpha}^{2}}{\left(\omega_{\alpha}^{2}-\omega^{2}-i \omega \gamma_{\alpha}\right)}
$$

where $\omega_{\alpha}$ and $\gamma_{\alpha}$ are the frequencies and natural widths of the uncoupled modes. The constant $\lambda_{\alpha}$ is a dimensionless coupling constant related to the electron-molecular vibration $(e-m v)$ coupling constant $g_{\alpha}$ by

$$
\lambda_{\alpha}=\frac{8 c_{1}^{2} g_{\alpha}^{2}}{\omega_{C T} \omega_{\alpha}}
$$

The real part of the scalar conductivity $\sigma(\omega)$ yields the CT excitation spectrum of the ionradical dimer, which consists of the primary $\mathrm{CT}$ excitation mode and a series of absorption bands in the region of the molecular frequencies $\left\{\omega_{\alpha}\right\}$. The latter are oscillations in the radical electron dipole moment driven by the antisymmetric vibrational modes $q_{\alpha}$ [8]. In order to obtain the microscopic parameters for the dimer, we have fitted $\operatorname{Re}[\sigma(\omega)]$ to the experimental spectra of $(\mathrm{DMtTTF}) \mathrm{Br}$ and $(o-\mathrm{DMTTF})_{2}\left[\mathrm{~W}_{6} \mathrm{O}_{19}\right]$. Figures 5 and 6 show the conductivity spectra obtained by a Kramers-Kronig transformation of the experimental reflectance spectra (upper panels) and the conductivity spectra calculated within the framework of the dimer model (lower panels). In Table 3, the model parameters for the fit to the E//a conductivity spectra of (DMtTTF) Br and $(o-\mathrm{DMTTF})_{2}\left[\mathrm{~W}_{6} \mathrm{O}_{19}\right]$ are presented and illustrate that the 
coupling constants for all three $\mathrm{C}=\mathrm{C}$ stretching modes were evaluated. In Table 4 , one can see that EMV coupling constants for TTF and its derivatives BEDT-TTF, DOEO $($ DOEO $=(1,4-$ dioxane-diyl-2,3-ditio)ethylenedioxytetrathiafulvalene), $\quad$ TMTTF $\quad$ (TMTTF $=$ tetramethlytetrathiafulvalene) and TTP (TTF = bis-fused TTF) compare closely to those determined for DMtTTF and $o$-DMTTF $[2,3,15,25,32,33]$. One can also see that the most strongly coupled modes are those assigned to vibrations of the TTF skeleton, i.e. the modes related to the stretching vibrations of both central and ring $\mathrm{C}=\mathrm{C}$ bonds. From the frequency and intensity of the CT transition we can also extract the values of the intradimer transfer

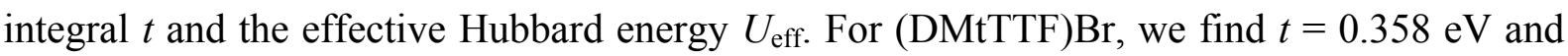
$U_{\text {eff }}=0.418 \mathrm{eV}$, while for $(o-\mathrm{DMTTF})_{2}\left[\mathrm{~W}_{6} \mathrm{O}_{19}\right] t=0.307 \mathrm{eV}$ and $U_{\text {eff }}=0.974 \mathrm{eV}$.

As mentioned previously, the charge transfer band in $(o \text {-DMTTF })_{2}\left[\mathrm{~W}_{6} \mathrm{O}_{19}\right]$ lies at larger frequency than that observed for (DMtTTF)Br, a fact that has an important consequence for both the $U_{\text {eff }}$ and EMV coupling parameters. When considering salts based on TTF derivatives, one might expect their charge transfer bands related to intermolecular electronic transitions between neighboring fully charged molecules occur at approximately the same frequency within their spectra. However, given that those bands might be influenced by the presence and magnitude of on-site Coulombic interactions, the actual frequencies for their charge transfer bands can be quite different [34]. For (o-DMTTF $)_{2}\left[\mathrm{~W}_{6} \mathrm{O}_{19}\right]$, observed at $10250 \mathrm{~cm}^{-1}$ is comparable to those found for salts based on DOEO [25], $\mathrm{M}(\mathrm{dddt})_{2}\left(\mathrm{M}=\mathrm{Pd}^{\mathrm{II}}\right.$, $\mathrm{Pt}^{\mathrm{II}}$ and $\mathrm{Ni}^{\mathrm{II}}$ [35-37] and BEDT-TTF [25,35-40]. Meanwhile, the considerably lower value of $7700 \mathrm{~cm}^{-1}$, observed in (DMtTTF)Br, is akin to those measured in $\mathrm{Ni}(\mathrm{dmit})_{2}$ and selected BEDT-TTF salts [41-43].

In order to investigate the differences between CT bands, we computed the highest occupied molecular orbitals (HOMO) for the $\mathrm{DMtTTF}^{\circ+}$ and $o$-DMTTF${ }^{\circ+}$ radical cations. Figure $7 \mathrm{a}$ reveals that the electron density distribution on atoms within the HOMO is 
observed in the central $\mathrm{C}_{2} \mathrm{~S}_{4}$ core of each donor. If the conduction band for (oDMTTF $)_{2}\left[\mathrm{~W}_{6} \mathrm{O}_{19}\right]$ and (DMtTTF)Br originates from the HOMO, we would expect delocalized conducting electrons to lie parallel to the stacking axis. The direct overlap of the individual $\mathrm{C}_{2} \mathrm{~S}_{4}$ cores from the $\mathrm{DMtTTF}^{\cdot+}$ and $o-\mathrm{DMTTF}^{\circ+}$ radicals with interplanar distances of 3.311 and $3.498 \AA$, respectively, (see Figure $7 b$ ) enables intermolecular electron transfer through the $\pi$-orbitals. Moreover, the intradimer distance among the donors in (DMtTTF) $\mathrm{Br}$ is smaller than that for $(o-\mathrm{DMTTF})_{2}\left[\mathrm{~W}_{6} \mathrm{O}_{19}\right]$ and suggests that the charge-transfer band for the former salt should lie at lower frequency than that for the latter.

In $(o \text {-DMTTF })_{2}\left[\mathrm{~W}_{6} \mathrm{O}_{19}\right]$, both $o$-DMTTF ${ }^{*+}$ cations within the dimer strongly interact with the $\left[\mathrm{W}_{6} \mathrm{O}_{19}\right]^{2-}$ anions via hydrogen bonding and suggest that this anion-donor interaction is not only responsible for different intradimer distances but also the position of chargetransfer band. For example, it is well known that strong anion-donor interaction can induce a shift of $\pi$-hole density and thus contribute to charge ordering effects in organic conductors based on TTF derivatives [44]. Therefore, it is possible that the charge density distribution on the $o-\mathrm{DMTTF}^{\circ+}$ radicals in $(o-\mathrm{DMTTF})_{2}\left[\mathrm{~W}_{6} \mathrm{O}_{19}\right]$ can be strongly affected by hydrogen bonding and that the evaluated molecular parameters for $o-\mathrm{DMTTF}^{{ }^{+}}$cations can be distorted by the anion-donor interaction. Additionally, on the basis of the DFT calculations, we observed that even for isolated $o$-DMTTF ${ }^{*+}$ cations, a large amount of positive charge is transferred from the TTF core to the outer part of the molecule (see Table V). This may in turn also influence the position of charge-transfer band, i.e. yield a shift toward higher frequencies.

\section{Conclusions}

In this paper, we have presented and discussed the infrared spectra of two recently synthesized charge-transfer salts $(\mathrm{DMtTTF}) \mathrm{Br}$ and $(o-\mathrm{DMTTF})_{2}\left[\mathrm{~W}_{6} \mathrm{O}_{19}\right]$ in which the donors 
form strongly dimerized stacks isolated from each other due to effective separation by their co-crystallized anions. Analysis of their IR and Raman spectra allowed us to obtain important information regarding their electronic and vibrational structure. Spectral features related to the electron-molecular vibration-coupling phenomena were analyzed in terms of the model for isolated doubly charged dimers and suitable coupling constants were estimated. The values of coupling constants obtained for $(\mathrm{DMtTTF}) \mathrm{Br}$ and $(o-\mathrm{DMTTF})_{2}\left[\mathrm{~W}_{6} \mathrm{O}_{19}\right]$ salts are comparable to those obtained for other TTF derivatives. We have shown that the most strongly coupled modes are due to the stretching vibrations of both central and ring $\mathrm{C}=\mathrm{C}$ bonds. Nevertheless, in the case of $(o \text {-DMTTF })_{2}\left[\mathrm{~W}_{6} \mathrm{O}_{19}\right]$, the evaluated parameters can be distorted by hydrogen bonding interactions between the $o-\mathrm{DMTTF}^{\circ+}$ radicals and the $\left[\mathrm{W}_{6} \mathrm{O}_{19}\right]^{2-}$ anions.

\section{Acknowledgements}

This work was supported by the National Science Centre (Decision No. DEC2012/04/M/ST3/00774).

\section{References}

[1] A. Girlando, M. Masino, A. Brillante, R.G. Della Valle, E. Venuti Phys. Rev. B 66 (2002) 100507(R).

[2] A. Painelli, A. Girlando, C. Pecile, Solid State Commun. 52 (1984) 801.

[3] A. Painelli, A. Girlando, J. Chem. Phys. 84 (1986) 5655.

[4] C. Pecile, A. Painelli, A. Girlando, Mol. Cryst. Liq. Cryst. 171 (1989) 69.

[5] M.J. Rice, Phys. Rev. Lett. 37 (1976) 36.

[6] M.J. Rice, L. Pietronero, and P. Brüesch, Solid State Commun. 21 (1977) 757.

[7] M.J. Rice, N.O. Lipari, and S. Strässler, Phys. Rev. Lett. 39 (1977) 1359.

[8] M.J. Rice, Solid State Commun. 31 (1979) 93.

[9] M.J. Rice, V.M. Yartsev, C.S. Jacobsen, Phys. Rev. B 21 (1980) 3437. 
[10] V.M. Yartsev, Phys. Stat. Sol. (b) 112 (1982) 279.

[11] V.M. Yartsev, Phys. Stat. Sol. (b) 126 (1984) 501.

[12] V.M. Yartsev, Phys. Stat. Sol. (b) 149 (1988) 157.

[13] V. M. Yarstev, R. Świetlik, Rev. Solid State Sci. 4 (1990) 69.

[14] V. M. Yartsev and A. Graja, Intern. J. Mod. Phys. B 12 (1998) 1643

[15] G. Visentini, M. Masino, C. Bellitto, A. Girlando, Phys. Rev. B 58 (1998) 9460.

[16] M.G. Kaplunov, Yu.G. Borodko, Khim. Fizika 6 (1987) 1529.

[17] M.V. Belousov, A.M. Vainrub, R.M. Vlasova, Fiz. Tverd. Tela 18 (1976) 2637.

[18] A. Girlando, R. Bozio, C. Pecile, J.B. Torrance, Phys. Rev. B 26 (1982) 2306.

[19] M.G. Kaplunov, R.N. Lyubovskaya, J. Phys. I France 2 (1992) 1811.

[20] E.W. Reinheimer, D. Jankowski, R. Świetlik, M. Fourmigué, J. Chem. Crystall. 43 (2013) 178 .

[21] P. Delhaes, C. Garrigou-Lagrange, and J.-M. Fabre, Physica B 143 (1986) 485.

[22] D. Jankowski, R. Świetlik, E.W. Reinheimer, M. Fourmigué, J. Raman Spectr. 42 (2011) 1518.

[23] D. Jankowski, R. Świetlik, E.W. Reinheimer, M. Fourmigué, Phys. Stat. Sol. (c) 9 (2012) 1164.

[24] D. Jankowski, R. Świetlik, O. Jeannin, A. Assaf, E.W. Reinheimer, and M. Fourmigué, J. Raman Spectrosc. - in press (2013)

[25] A. Łapiński, A. Kotov, Chem. Phys. 326 (2006) 551.

[26] O. Drozdova, K. Yakushi, K. Yamamoto, A. Ota, H. Yamochi, G. Saito, H. Tashiro, D.B. Tanner, Phys. Rev. B 70 (2004) 075107.

[27] Gaussian 03, Revision B.05, M. J. Frisch, G. W. Trucks, H. B. Schlegel, G. E. Scuseria, M. A. Robb, J. R. Cheeseman, J. A. Montgomery, Jr., T. Vreven, K. N. Kudin, J. C. Burant, J. M. Millam, S. S. Iyengar, J. Tomasi, V. Barone, B. Mennucci, M. Cossi, G. Scalmani, N. 
Rega, G. A. Petersson, H. Nakatsuji, M. Hada, M. Ehara, K. Toyota, R. Fukuda, J. Hasegawa, M. Ishida, T. Nakajima, Y. Honda, O. Kitao, H. Nakai, M. Klene, X. Li, J. E. Knox, H. P. Hratchian, J. B. Cross, C. Adamo, J. Jaramillo, R. Gomperts, R. E. Stratmann, O. Yazyev, A. J. Austin, R. Cammi, C. Pomelli, J. W. Ochterski, P. Y. Ayala, K. Morokuma, G. A. Voth, P. Salvador, J. J. Dannenberg, V. G. Zakrzewski, S. Dapprich, A. D. Daniels, M. C. Strain, O. Farkas, D. K. Malick, A. D. Rabuck, K. Raghavachari, J. B. Foresman, J. V. Ortiz, Q. Cui, A. G. Baboul, S. Clifford, J. Cioslowski, B. B. Stefanov, G. Liu, A. Liashenko, P. Piskorz, I. Komaromi, R. L. Martin, D. J. Fox, T. Keith, M. A. Al-Laham, C. Y. Peng, A. Nanayakkara, M. Challacombe, P. M. W. Gill, B. Johnson, W. Chen, M. W. Wong, C. Gonzalez, and J. A. Pople, Gaussian, Inc., Pittsburgh PA, (2003).

[28] A.D. Becke J. Chem. Phys. 98 (1993) 5648.

[29] C. Lee, W. Yang, R.G. Parr Phys. Rev. B 37 (1988) 785.

[30] U. Fano, Phys. Rev. 124 (1961) 1866.

[31] B. Horovitz, H. Gutfreund, M. Weger, Phys. Rev. B 17 (1978) 2796.

[32] D. Pedron, R. Bozio, M. Meneghetti, C. Pecile, Phys. Rev. B 49 (1994) 10893.

[33] M. Taniguchi, Y. Misaki, K. Tanaka, Solid State Commun. 114 (2000) 75.

[34] J. Hubbard, Phys. Rev. B 17 (1978) 494.

[35] A. Łapiński, R. Świetlik, Phys. Rev. B 59 (1999) 15669.

[36] M.G. Kaplunov, A.I. Kotov, E.B. Yagubskii, Synth. Met. 44 (1991) 213.

[37] R. Świetlik, L.A. Kushch, E.B. Yagubskii, Synth. Met. 70 (1995) 1053.

[38] R. Świetlik, N.D. Kushch, L.A. Kushch, E.B. Yagubskii, Phys. Stat. Sol. (b) 181 (1994) 499.

[39] A. Łapiński, A. Graja, T.G. Prokhorova, J. Mol. Structure 704 (2004) 83.

[40] A. Ugawa, G. Ojima, K. Yakushi, H. Kuroda, Phys. Rev. B 38 (1998) 5122. 
[41] H.L. Liu, D.B. Tanner, A.E. Pullen, K.A. Abboud, J.R. Reynolds, Phys. Rev. B 53 (1996) 10557.

[42] A. Łapiński, V. Starodub, M. Golub, A. Kravchenko, V. Baumer, E. Faulques, A. Graja, Synth. Met. 138 (2003) 483.

[43] R. Świetlik, A. Łapiński, L. Ouahab, K. Yakushi, C.R. Chimie 6 (2003) 395.

[44] J.-P. Pouget, P. Foury-Leylekian, P. Alemany, E. Canadell, Phys. Stat. Sol. (b) 249 (2012) 937. 


\section{Figure captions}

Figure 1. Structure of (DMtTTF)Br: (a) projection view of the unit cell along the $a$ axis, showing the absence of inter-stack interactions and (b) side view of the strongly dimerized stacks running along the $a$-axis.

Figure 2. Crystal structure of $(o-\mathrm{DMTTF})_{2}\left[\mathrm{~W}_{6} \mathrm{O}_{19}\right]$.

Figure 3. Raman spectrum of the 1:1 salt (DMtTTF)Br recorded for the electrical vector of the exciting laser beam $\left(\lambda_{\mathrm{exc}}=632.8 \mathrm{~nm}\right)$ parallel to the direction of maximum intensity of the band at $1412 \mathrm{~cm}^{-1}(\mathrm{C}=\mathrm{C}$ stretching), i.e. perpendicular to the $a$-direction.

Figure 4. Room temperature reflectance spectra of (DMtTTF) Br (a) and (o-DMTTF) ${ }_{2}\left[\mathrm{~W}_{6} \mathrm{O}_{19}\right]$ (b) salts recorded for polarization parallel $(\mathrm{E} / / a)$ and perpendicular $(\mathrm{E} \perp a)$ to the stacking $a$ axis. Note the logarithmic wavenumber scale.

Figure 5. Experimental and calculated conductivity spectra of (DMtTTF)Br salt. Note that the electric vector is parallel to the stacking axis and the logarithmic wavenumber scale.

Figure 6. Experimental and calculated conductivity spectra of $(o-\mathrm{DMTTF})_{2}\left[\mathrm{~W}_{6} \mathrm{O}_{19}\right]$ salt. Note that the electric vector is parallel to the stacking axis and the logarithmic wavenumber scale.

Figure 7. Sketch of the HOMO orbital of the $\mathrm{DMtTTF}^{\circ+}$ and $\mathrm{DMTTF}^{\circ+}$ cations computed at the B3LYP/6-311++G(d,p) level of theory (a). Packing arrangements within the stacks observed for the (o-DMTTF $)_{2}\left[\mathrm{~W}_{6} \mathrm{O}_{19}\right]$ and (DMtTTF)Br salts (b). 
(a)

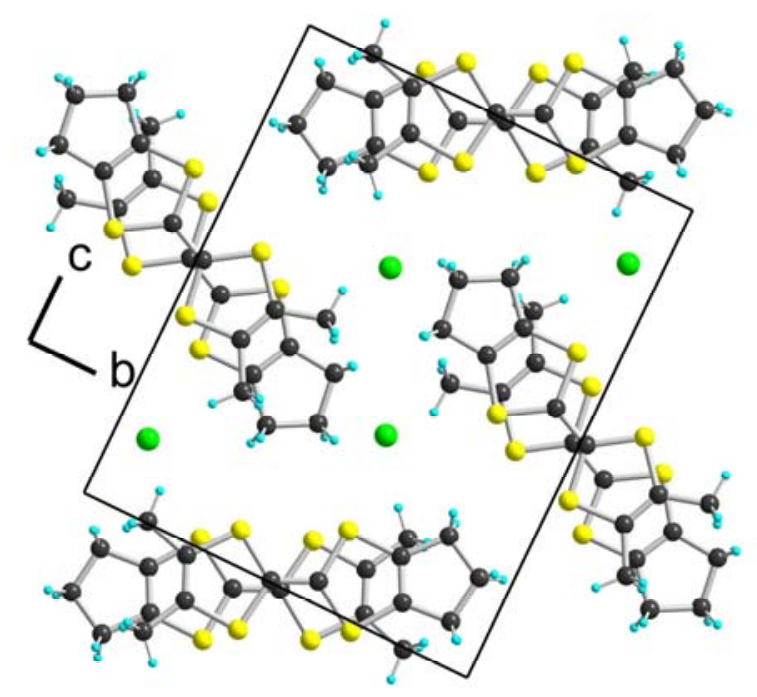

(b)

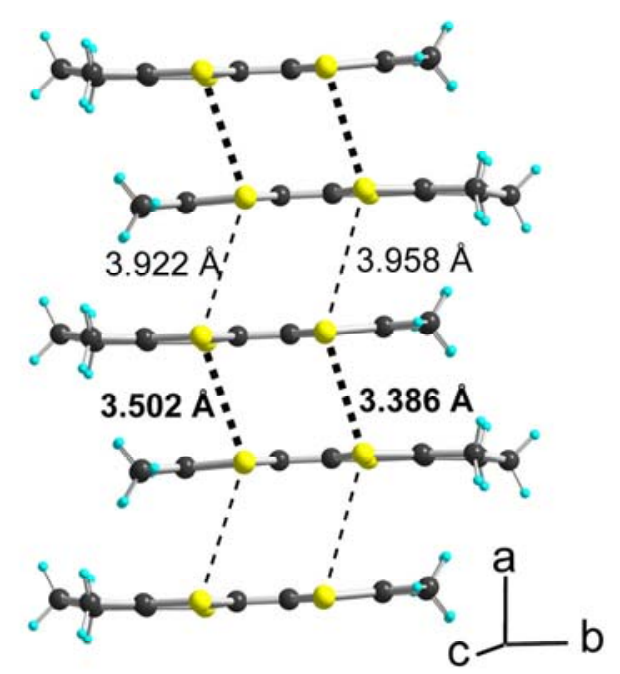

Figure 1. Structure of (DMtTTF)Br: (a) projection view of the unit cell along the $a$ axis, showing the absence of inter-stack interactions and (b) side view of the strongly dimerized stacks running along the $a$-axis. 


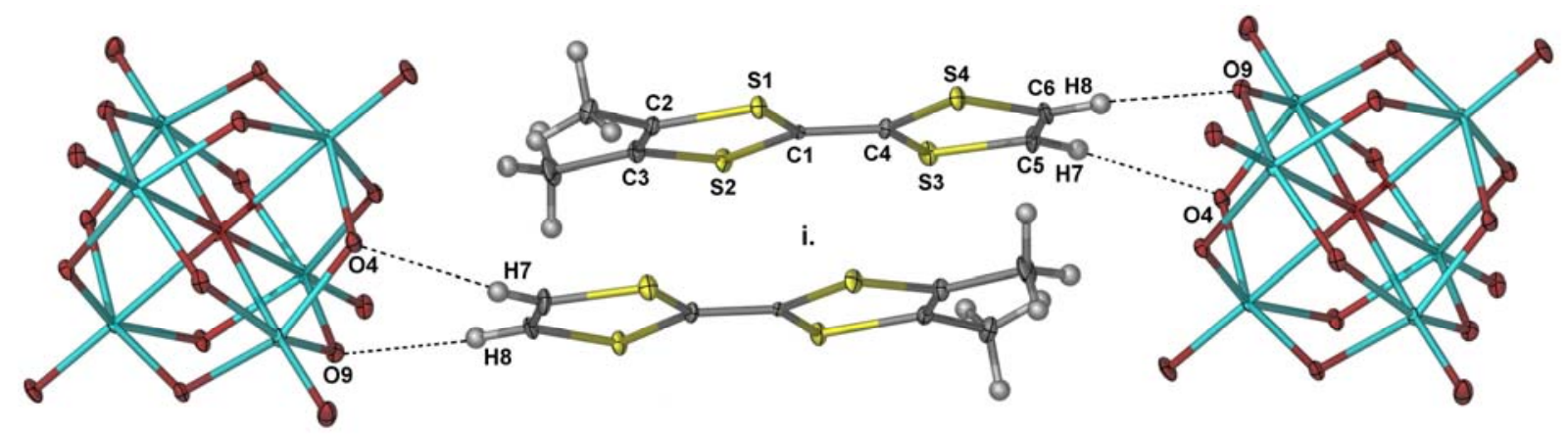

Figure 2. Crystal structure of $(o-\mathrm{DMTTF})_{2}\left[\mathrm{~W}_{6} \mathrm{O}_{19}\right]$. 


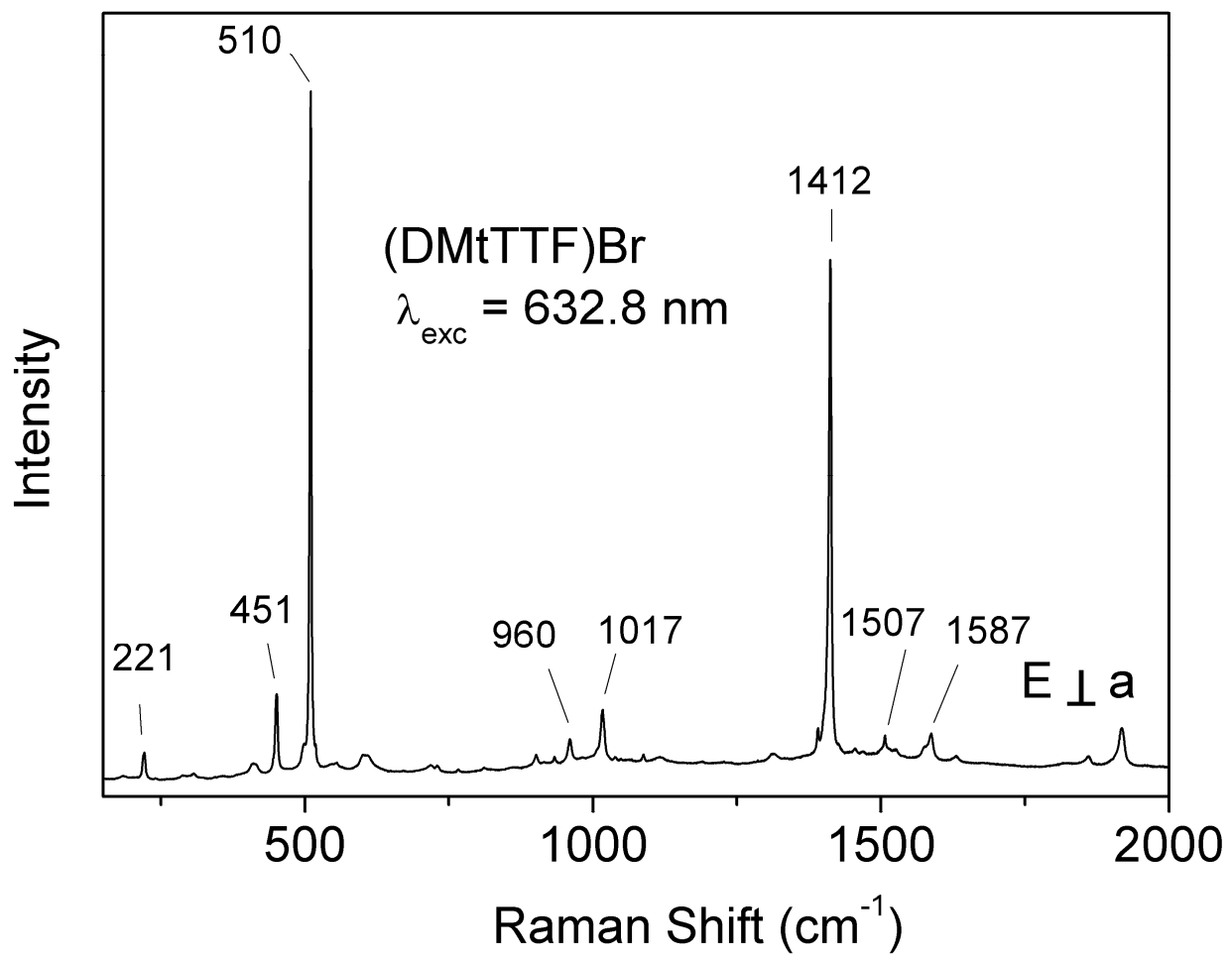

Figure 3. Raman spectrum of the 1:1 salt (DMtTTF)Br recorded for the electrical vector of the exciting laser beam $\left(\lambda_{\mathrm{exc}}=632.8 \mathrm{~nm}\right)$ parallel to the direction of maximum intensity of the band at $1412 \mathrm{~cm}^{-1}(\mathrm{C}=\mathrm{C}$ stretching $)$, i.e. perpendicular to the $a$-direction. 


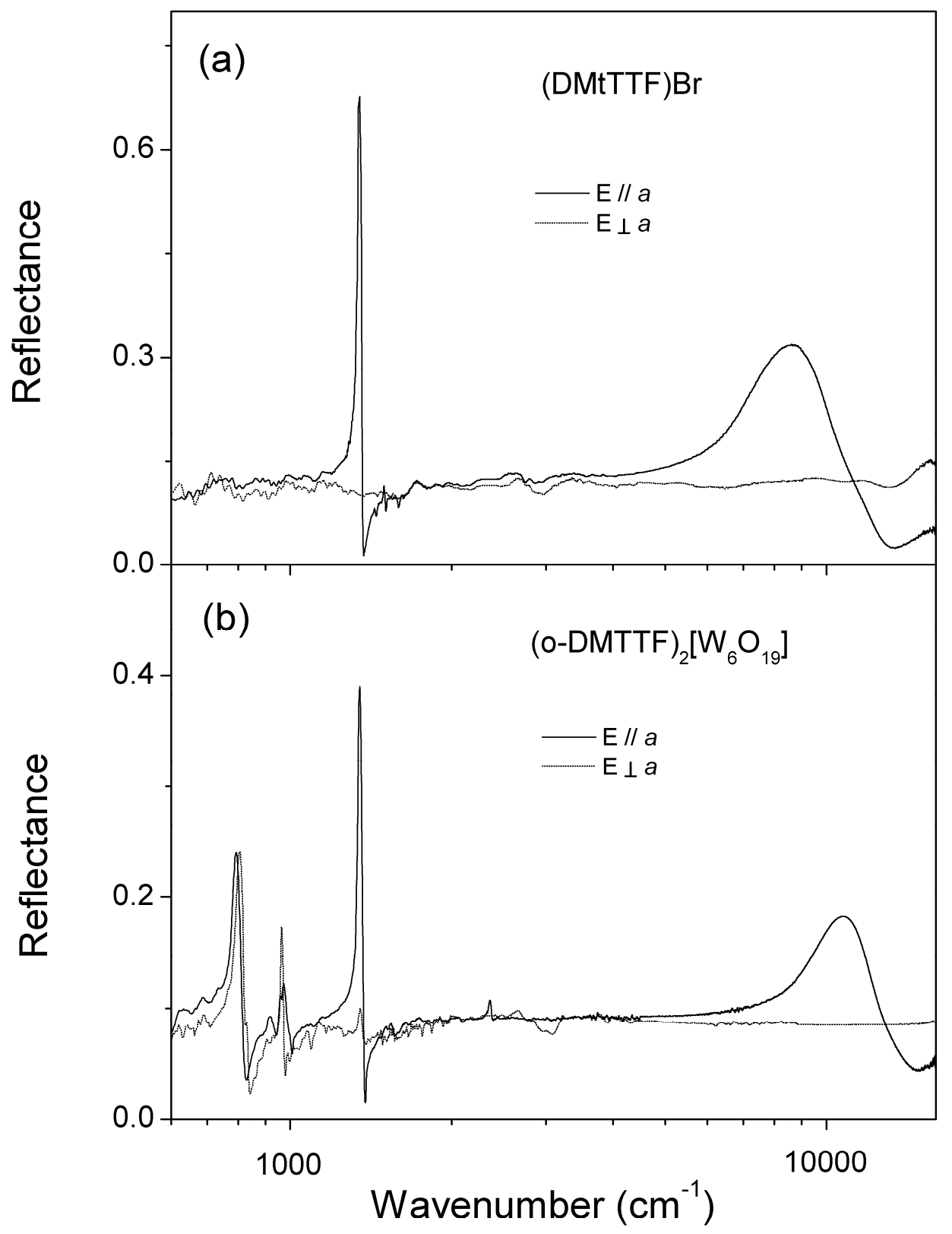

Figure 4. Room temperature reflectance spectra of (DMtTTF) Br (a) and $(o-\mathrm{DMTTF})_{2}\left[\mathrm{~W}_{6} \mathrm{O}_{19}\right]$ (b) salts recorded for polarization parallel $(\mathrm{E} / / a)$ and perpendicular $(\mathrm{E} \perp a)$ to the stacking $a$ axis. Note the logarithmic wavenumber scale. 


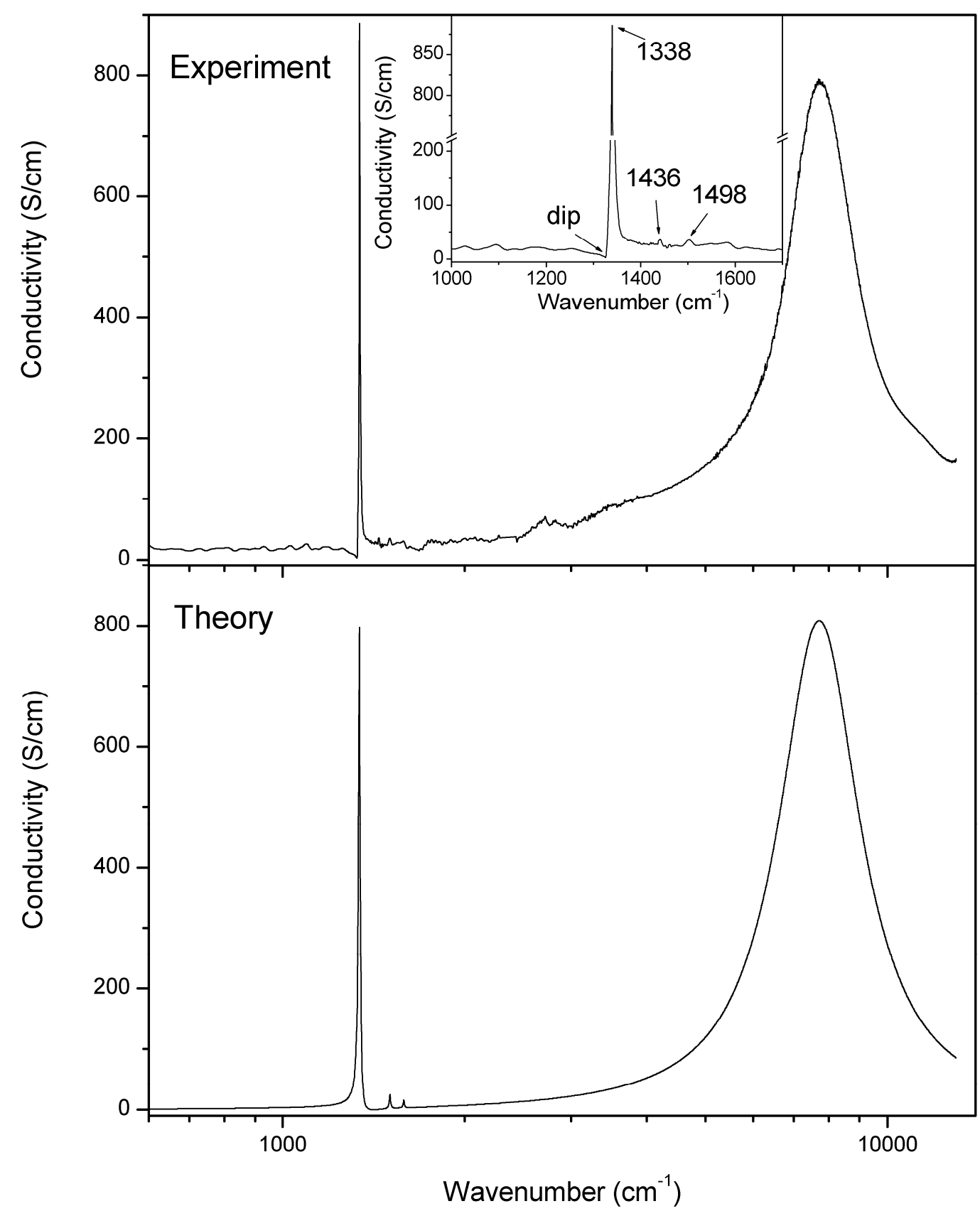

Figure 5. Experimental and calculated conductivity spectra of (DMtTTF)Br salt. Note that the electric vector is parallel to the stacking axis and the logarithmic wavenumber scale. 


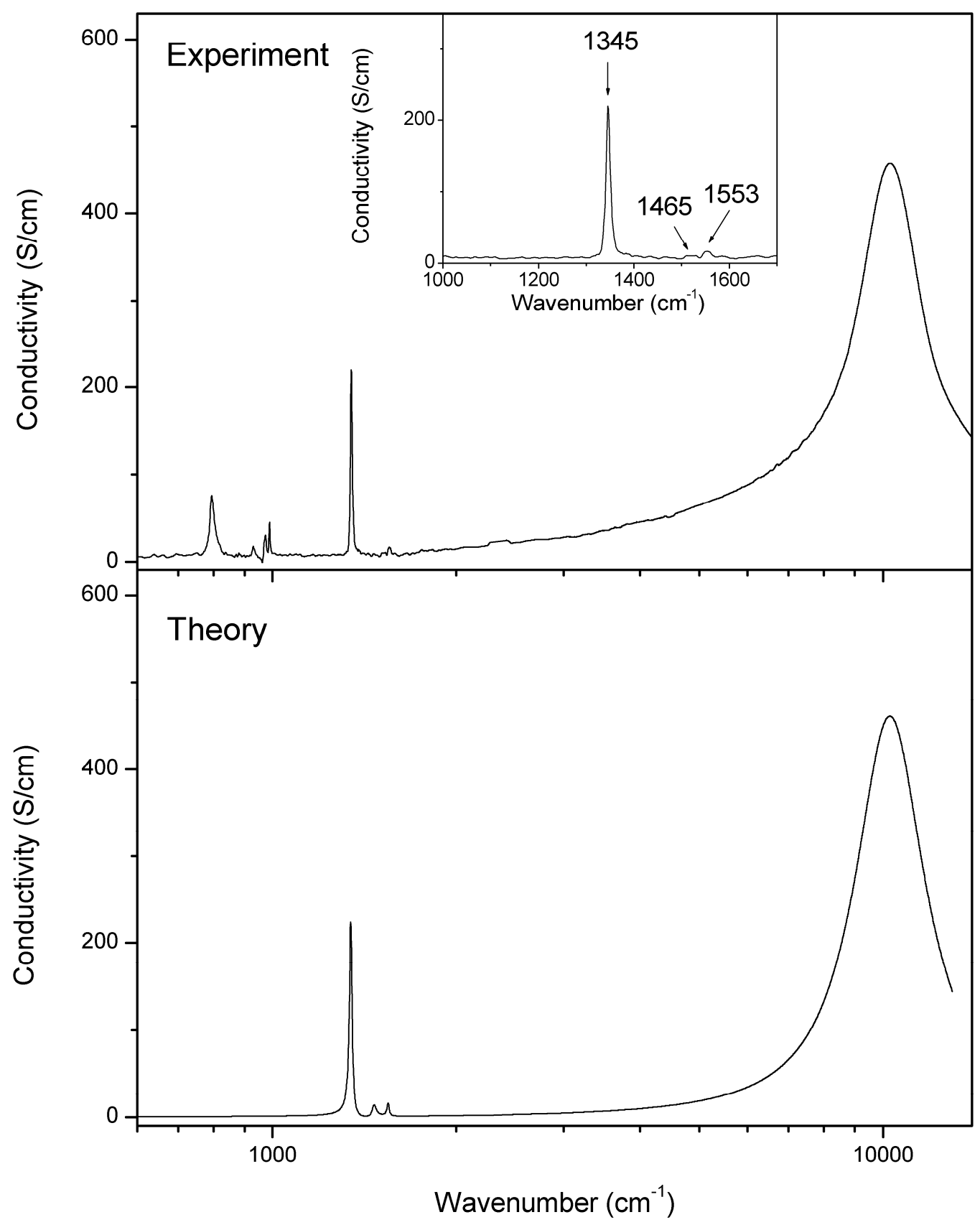

Figure 6. Experimental and calculated conductivity spectra of $(o-\mathrm{DMTTF})_{2}\left[\mathrm{~W}_{6} \mathrm{O}_{19}\right]$ salt. Note that the electric vector is parallel to the stacking axis and the logarithmic wavenumber scale. 
DMtTTF $^{+}$

(a)

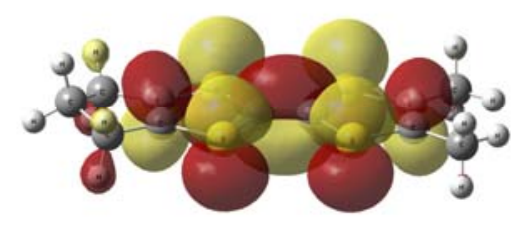

HOMO
DMTTF $^{+}$

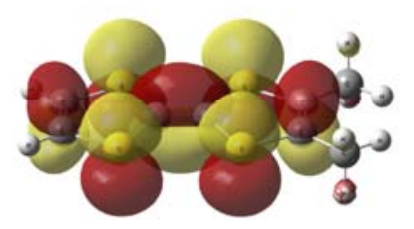

HOMO
(DMtTTF)Br

(b)
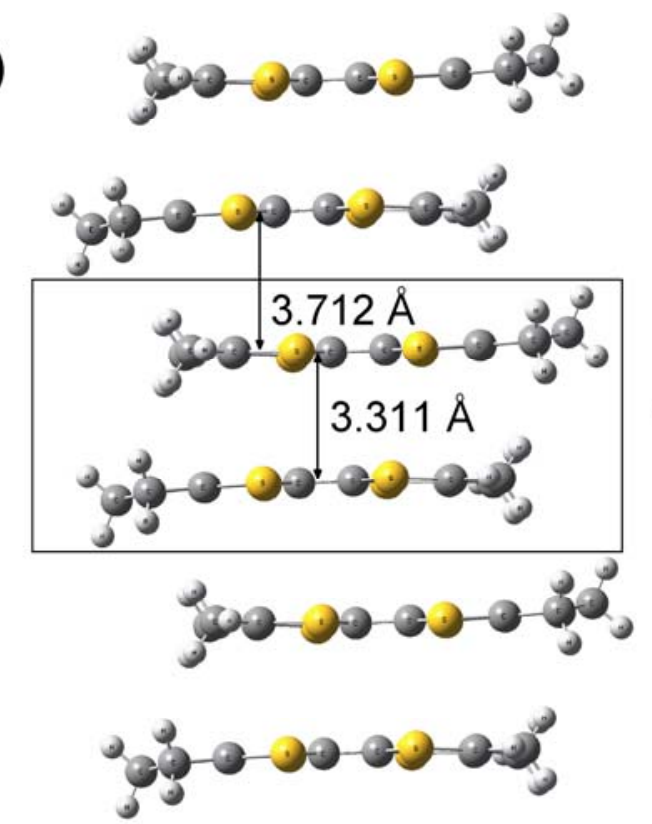

(o-DMTTF $)_{2}\left[\mathrm{~W}_{6} \mathrm{O}_{19}\right]$

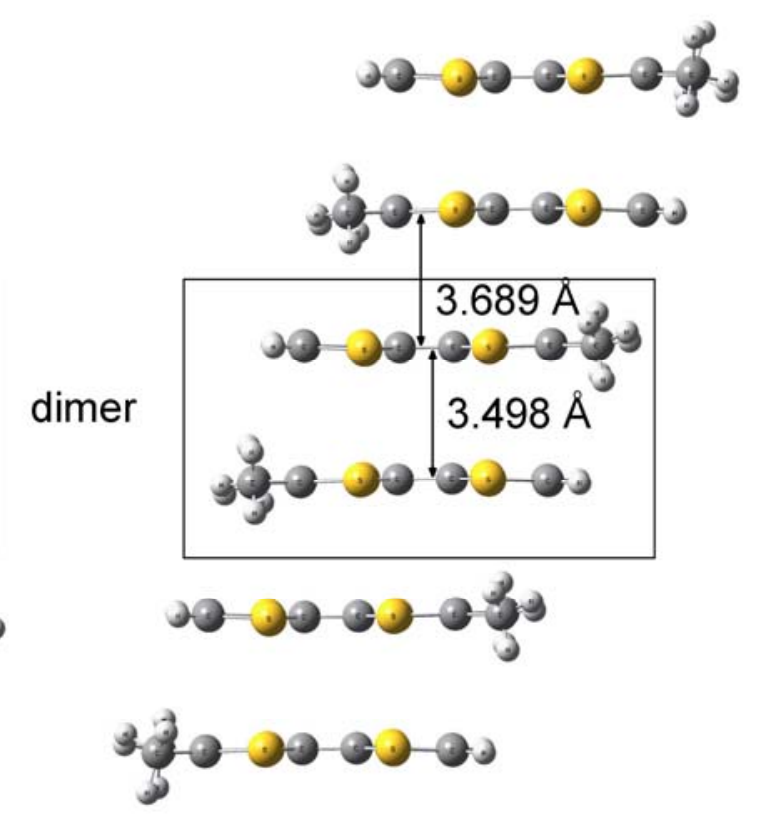

Figure 7. Sketch of the HOMO orbital of the $\mathrm{DMtTTF}^{\circ+}$ and $\mathrm{DMTTF}^{\circ+}$ cations computed at the B3LYP/6-311++G(d,p) level of theory (a). Packing arrangements within the stacks observed for the (o-DMTTF $)_{2}\left[\mathrm{~W}_{6} \mathrm{O}_{19}\right]$ and (DMtTTF)Br salts (b). 


\section{Tables}

Table I. Room temperature crystallographic data of the salt (DMtTTF)Br

\begin{tabular}{|c|c|}
\hline Compound & (DMtTTF)Br \\
\hline Formula & $\mathrm{C}_{11} \mathrm{H}_{12} \mathrm{BrS}_{4}$ \\
\hline $\mathrm{FW}\left(\mathrm{g} \cdot \mathrm{mol}^{-1}\right)$ & 352.39 \\
\hline Crystal color & Black \\
\hline Crystal size (mm) & $0.3 \times 0.3 \times 0.1$ \\
\hline Crystal system & Monoclinic \\
\hline Space group & $\mathrm{P} 2{ }_{1} / \mathrm{c}$ \\
\hline $\mathrm{T}(\mathrm{K})$ & $293(2)$ \\
\hline $\mathrm{a}(\AA)$ & $7.0259(8)$ \\
\hline $\mathrm{b}(\AA)$ & $12.4074(11$ \\
\hline c $(\AA)$ & $15.4574(16)$ \\
\hline$\alpha\left({ }^{\circ}\right)$ & 90.0 \\
\hline$\beta\left(^{\circ}\right)$ & $101.684(9)$ \\
\hline$\gamma\left({ }^{\circ}\right)$ & 90.0 \\
\hline $\mathrm{V}\left(\AA^{3}\right)$ & $1319.6(2)$ \\
\hline Z & 4 \\
\hline Dcalc $\left(\mathrm{g} \cdot \mathrm{cm}^{-3}\right)$ & 1.774 \\
\hline$\mu\left(\mathrm{mm}^{-1}\right)$ & 3.717 \\
\hline Total refls. & 6878 \\
\hline Absorption correction & multi-scan \\
\hline $\mathrm{T}_{\min }, \mathrm{T}_{\max }$ & $0.647,0.690$ \\
\hline Unique refls. & 2977 \\
\hline Rint & 0.0316 \\
\hline $\begin{array}{l}\text { Unique refls. } \\
(\mathrm{I}>2 \sigma(\mathrm{I}))\end{array}$ & 2311 \\
\hline Refined param. & 146 \\
\hline $\mathrm{R}_{1}(\mathrm{I}>2 \sigma(\mathrm{I}))$ & 0.0503 \\
\hline $\mathrm{wR}_{2}$ (all data) & 0.1355 \\
\hline Goodness-of-fit & 1.117 \\
\hline Res. dens $\left(\mathrm{e}^{-} \AA^{-3}\right)$ & $-0.616,0.614$ \\
\hline
\end{tabular}


Table II. Intramolecular bond lengths (averaged) within the TTF core.

\begin{tabular}{|l|l|l|l|}
\hline \hline $\mathrm{C}_{\mathrm{i}}=\mathrm{C}_{\mathrm{i}}(\AA)$ & \multicolumn{1}{|c|}{$\mathrm{C}_{\mathrm{i}}-\mathrm{S}(\AA)$} & $\mathrm{C}_{\mathrm{o}}-\mathrm{S}(\AA)$ & $\mathrm{C}_{\mathrm{o}}=\mathrm{C}_{\mathrm{o}}(\AA)$ \\
\hline $1.389(7)$ & $1.731(5)(\mathrm{R})$ & $1.721(5)(\mathrm{R})$ & $1.349(7)(\mathrm{R})$ \\
& $1.720(5)(\mathrm{Me})$ & $1.752(6)(\mathrm{Me})$ & $1.329(9)(\mathrm{Me})$ \\
\hline
\end{tabular}

$\left(\mathrm{C}_{\mathrm{i}}\right.$ represents the inner carbon atoms of the TTF core, $\mathrm{C}_{\mathrm{o}}$ the outer ones; $\mathrm{R}$ the fivemembered ring side; Me the methyl side). 


\section{Table III}

Dimer model parameters for the fit to the polarized conductivity spectrum of (DMtTTF) Br and $(o \text {-DMTTF })_{2}\left[\mathrm{~W}_{6} \mathrm{O}_{19}\right]$ obtained by Kramers-Kronig transformation from the reflectance spectra.

\begin{tabular}{|c|c|c|c|c|c|c|}
\hline \multicolumn{3}{|c|}{ (DMtTTF)Br ${ }^{\mathrm{a}}$} & \multicolumn{3}{|c|}{ 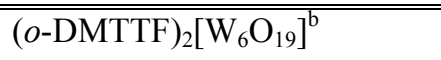 } & \multirow[b]{2}{*}{ Assignment } \\
\hline$\omega_{\alpha}\left(\mathrm{cm}^{-1}\right)$ & $g_{\alpha}(\mathrm{meV})$ & $\lambda_{\alpha}$ & $\omega_{\alpha}\left(\mathrm{cm}^{-1}\right)$ & $g_{\alpha}(\mathrm{meV})$ & $\lambda_{\alpha}$ & \\
\hline 1587 & 12 & 0.002 & 1556 & 60 & 0.022 & in-phase ring $\mathrm{C}=\mathrm{C}$ stretch \\
\hline 1507 & 20 & 0.006 & 1483 & 80 & 0.042 & anti-phase ring $\mathrm{C}=\mathrm{C}$ stretch \\
\hline 1412 & 74 & 0.095 & 1417 & 100 & 0.068 & central $\mathrm{C}=\mathrm{C}$ stretch \\
\hline
\end{tabular}

$\overline{\mathrm{a}} a=3.311 \AA, \mathrm{N}=2, V=1319.62 \AA^{3}, c_{1}=0.600, \omega_{\mathrm{CT}}=7700 \mathrm{~cm}^{-1}, \gamma_{\mathrm{e}}=2900 \mathrm{~cm}^{-1}$

${ }^{\mathrm{b}} a=3.498 \AA, \mathrm{N}=1, V=802.10 \AA^{3}, c_{l}=0.435, \omega_{\mathrm{CT}}=10250 \mathrm{~cm}^{-1}, \gamma_{\mathrm{e}}=3310 \mathrm{~cm}^{-1}$

$\left(U_{\text {eff }} / 4 t\right.$ equals $x a=0.292$ and $\mathrm{xb}=0.793$ for $(\mathrm{DMtTTF}) \mathrm{Br}$ and $(o-\mathrm{DMTTF})_{2}\left[\mathrm{~W}_{6} \mathrm{O}_{19}\right]$ salts, respectively $)$ 


\section{Table IV}

The EMV coupling constants, $g_{\alpha}(\mathrm{meV})$ of the $\mathrm{C}=\mathrm{C}$ stretching modes $\omega\left(\mathrm{cm}^{-1}\right)$ for several TTF-based radical cations.

\begin{tabular}{|c|c|c|c|c|c|c|c|c|c|}
\hline \multicolumn{2}{|c|}{$\mathrm{TTF}^{\bullet+}[2,3]$} & \multicolumn{2}{|c|}{ BEDT-TTF $^{*+}[15]$} & \multicolumn{2}{|c|}{ TMTTF $^{*+}[37]$} & \multicolumn{2}{|c|}{ TTP $^{\bullet+}[38]$} & \multicolumn{2}{|c|}{$\mathrm{DOEO}^{\cdot+}[30]$} \\
\hline$\omega$ & $g_{\alpha}$ & $\omega$ & $g_{\alpha}$ & $\omega$ & $g_{\alpha}$ & $\omega$ & $g_{\alpha}$ & $\omega$ & $g_{\alpha}$ \\
\hline \multirow[t]{2}{*}{1505} & 42 & 1460 & 43 & 1567 & 32 & 1540 & 8 & 1575 & 23 \\
\hline & & & & & & 1474 & 54 & 1494 & 31 \\
\hline 1420 & 133 & 1414 & 71 & 1418 & 133 & 1423 & 9 & 1460 & 29 \\
\hline
\end{tabular}




\section{Table V.}

Charge distribution (Mulliken) on atoms of TTF core calculated at the B3LYP/6-311++G(d,p) for $\mathrm{DMtTTF}^{*+}$ and $o$-DMTTF${ }^{\circ+}$ cations. Note: the numbering of atoms is shown in Fig. 2

\begin{tabular}{lrr}
\hline \hline Atom & DMtTTF $^{*+}$ & $o$-DMTTF \\
\hline C1 & 0.737 & 0.575 \\
S1 & -0.615 & -0.624 \\
S2 & -0.615 & -0.624 \\
C2 & 0.378 & 0.34 \\
C3 & 0.378 & 0.34 \\
C4 & 0.618 & 0.585 \\
S3 & -0.446 & -0.177 \\
S4 & -0.446 & -0.177 \\
C5 & 0.65 & -0.075 \\
C6 & 0.65 & -0.075 \\
\hline$\sum\left(\mathrm{C}_{6} \mathrm{~S}_{4}\right)$ & 1.289 & 0.088 \\
\hline \hline
\end{tabular}

